\title{
Editorial: Applying Margin Consensus Guidelines to Invasive Lobular Carcinoma of the Breast
}

\author{
Rita A. Mukhtar, MD ${ }^{1}$ \\ Department of Surgery, University of California, San Francisco, San Francisco, CA
}

In their recent study, "Was reexcision less frequent in patients with lobular breast cancer after publication of the SSO-ASTRO margin guidelines," Mamtani et al. show that women with invasive lobular carcinoma (ILC) indeed had lower rates of second surgery after adoption of new consensus guidelines at their center. ${ }^{1}$ Before guideline adoption, $31.4 \%$ of patients in their large series of ILC had either reexcision or completion mastectomy after breastconserving surgery. After guideline implementation in 2014 , this second surgery rate decreased to $23.1 \%$, a drop of similar magnitude to that seen in patients with invasive ductal carcinoma (IDC). A reduction in reexcisions was not necessarily expected for the following reasons: many surgeons have questioned the safety of narrow margins in ILC because of its growth pattern; additionally, there is a paucity of data on outcomes of narrow margins in this tumor type. However, women with ILC have such high rates of reexcisions and completion mastectomies that these findings could represent a meaningful improvement in their care.

Before publication of consensus guidelines, the definition of "negative margins" after surgical excision of breast cancer varied widely. ${ }^{2-4}$ In 2014, the Society of Surgical Oncology (SSO) and the American Society for Radiation Oncology (ASTRO) published consensus guidelines based on meta-analyses of nearly 30,000 patients who underwent breast conserving surgery for stage 1-2 invasive carcinoma. ${ }^{4}$ In brief, the guidelines state that negative margins defined as "no ink on tumor" provide the same control for

(C) Society of Surgical Oncology 2019

First Received: 7 July 2019;

Published Online: 4 September 2019

R. A. Mukhtar, MD

e-mail: Rita.mukhtar@ucsf.edu ipsilateral breast tumor recurrence as wider margins; this recommendation was made for all tumor subtypes, including ILC. $^{5}$ Many centers readily adopted these guidelines, with several publications showing reductions in overall re-excision rates after their implementation in 2014. However, these studies included predominantly patients with IDC. ${ }^{6-8}$ Consequently, the impact of the consensus guidelines on reexcision rates for women with ILC had not been thoroughly evaluated until the study of Mamtani et al.

Concerns about the diffuse growth pattern and multicentricity seen in ILC have made some question the safety of narrow margins in this histologic subtype. Lacking the adhesion protein E-cadherin, ILC often grows in "single file lines" and is difficult to detect on imaging. 9,10 The concern that tumor multicentricity could result in a negative margin but leave residual tumor in the breast has led some to advocate for wider margins in ILC, or even avoidance of breast conservation altogether. ${ }^{11-14}$

Although ILC has features that make the study of margin width particularly salient, there are relatively few studies of this topic in ILC. Among the patients included in the meta-analysis supporting the SSO-ASTRO consensus guidelines, fewer than $10 \%$ were reported to have either mixed or pure ILC, with the number of studies that reported recurrence rates specifically for ILC patients even smaller. At the time of consensus statement publication, data comparing recurrence rates between narrow margins $(<2 \mathrm{~mm})$ and wider margins were sparse. A study from Galimberti et al. showed the safety of margins smaller than $1 \mathrm{~cm}$ in ILC, but this definition is much larger than "no ink on tumor." 13

However, since publication of consensus guidelines, groups are beginning to report outcomes for ipsilateral breast tumor recurrence in ILC in the setting of margins in the $<1-\mathrm{mm}$ and 1-3-mm range. In two such series of 
mixed and pure ILC patients, recurrence rates in these groups are similar to patients with wider margins, providing support for the safety of this approach. ${ }^{15,16}$

Sparing patients additional surgery is significant for patients with ILC, who face much higher rates of reexcisions and completion mastectomies than patients with IDC. Since the time course for recurrence in ILC is typically long, many years of follow-up for these patients will be needed to definitively determine the impact of narrow margins. ${ }^{10}$ However, given continued improvements in systemic therapies, and development of imaging modalities that promise to improve detection for ER positive tumors, any potential benefit of wider margins is likely to become even smaller.

The data reported by Mamtani et al. importantly show that application of the margin consensus guidelines can result in significantly fewer reexcisions for patients with ILC. Future studies on the application of these guidelines to ILC patients in other centers would be of interest, and more data on long-term outcomes of these patients will hopefully confirm the safety of this approach.

\section{REFERENCES}

1. Mamtani AZ, Rosenberger E, Stempel L, et al. Was re-excision less frequent in patients with lobular breast cancer after publication of the SSO-ASTRO margin guidelines? Ann Surg Oncol. 2019 (in press).

2. Behm EC, Beckmann KR, Dahlstrom JE, Zhang Y, Cho C, Stuart-Harris R, et al. Surgical margins and risk of locoregional recurrence in invasive breast cancer: an analysis of 10-year data from the Breast Cancer Treatment Quality Assurance Project. Breast. 2013;22(5):839-44.

3. Havel L, Naik H, Ramirez L, Morrow M, Landercasper J, et al. Impact of the SSO-ASTRO margin guideline on rates of re-excision after lumpectomy for breast cancer: a meta-analysis. Ann Surg Oncol. 2019;26(5):1238-44.

4. Houssami N, Macaskill P, Marinovich ML, Morrow M, et al. The association of surgical margins and local recurrence in women with early-stage invasive breast cancer treated with breast-conserving therapy: a meta-analysis. Ann Surg Oncol. 2014;21(3):717-30.

5. Chung A, Gangi A, Amersi F, Bose S, Zhang X, Giuliano A, et al. Impact of Consensus Guidelines by the Society of Surgical Oncology and the American Society for Radiation Oncology on margins for breast-conserving surgery in stages 1 and 2 invasive breast cancer. Ann Surg Oncol. 2015;22(Suppl 3):S422-7.

6. Monaghan A, Chapinal N, Hughes L, Baliski C, et al. Impact of SSO-ASTRO margin guidelines on reoperation rates following breast-conserving surgery. Am J Surg. 2019;217(5):862-7.

7. Rosenberger LH, Mamtani A, Fuzesi S, Stempel M, Eaton A, Morrow M, et al. Early adoption of the SSO-ASTRO Consensus Guidelines on margins for breast-conserving surgery with wholebreast irradiation in stage I and II invasive breast cancer: initial experience from Memorial Sloan Kettering Cancer Center. Ann Surg Oncol. 2016;23(10):3239-46.

8. Schulman AM, Mirrielees JA, Leverson G, Landercasper J, Greenberg C, Wilke LG, et al. Reexcision surgery for breast cancer: an analysis of the American Society of Breast Surgeons (ASBrS) Mastery(SM) Database Following the SSO-ASTRO "No Ink on Tumor" Guidelines. Ann Surg Oncol. 2017;24(1):52-8.

9. Johnson K, Sarma D, Hwang ES. Lobular breast cancer series: imaging. Breast Cancer Res. 2015;17:94.

10. Mamtani A, King TA. Lobular breast cancer: different disease, different algorithms? Surg Oncol Clin N Am. 2018;27(1):81-94.

11. Houvenaeghel G, Tallet A, Jalaguier-Coudray A, Cohen M, Bannier M, Jauffret-Fara C, et al. Is breast conservative surgery a reasonable option in multifocal or multicentric tumors? World $J$ Clin Oncol. 2016;7(2):234-42.

12. Hussien M, Lioe TF, Finnegan J, Spence RA, et al. Surgical treatment for invasive lobular carcinoma of the breast. Breast. 2003;12(1):23-35

13. Galimberti V, Maisonneuve P, Rotmensz N, Viale G, Sangalli C, Sargenti M, et al. Influence of margin status on outcomes in lobular carcinoma: experience of the European Institute of Oncology. Ann Surg. 2011;253(3):580-4.

14. DeSnyder SM, Hunt KK, Smith BD, Moran MS, Klimberg S, Lucci A, et al. Assessment of practice patterns following publication of the SSO-ASTRO Consensus Guideline on margins for breast-conserving therapy in stage I and II invasive breast cancer. Ann Surg Oncol. 2015;22(10):3250-6.

15. Braunstein LZ, Brock JE, Chen YH, Truong L, Russo AL, Arvold $\mathrm{ND}$, et al. Invasive lobular carcinoma of the breast: local recurrence after breast-conserving therapy by subtype approximation and surgical margin. Breast Cancer Res Treat. 2015;149(2):555-64.

16. Sagara Y, Barry WT, Mallory MA, Vaz-Luis I, Aydogan F, Brock JE, et al. Surgical options and locoregional recurrence in patients diagnosed with invasive lobular carcinoma of the breast. Ann Surg Oncol. 2015;22(13):4280-6.

Publisher's Note Springer Nature remains neutral with regard to jurisdictional claims in published maps and institutional affiliations. 